\title{
Baseline respiration and spontaneous activity of sluggish marine tropical fish of the family Scorpaenidae
}

\author{
Christopher Zimmermann ${ }^{1,2, *}$, Andreas Kunzmann ${ }^{1,3}$ \\ ${ }^{1}$ Institut für Polarökologie der Universität Kiel, Wischhofstr. 1-3, Geb. 12, 24148 Kiel, Germany \\ ${ }^{2}$ Institut für Seefischerei, Bundesforschungsanstalt für Fischerei, Palmaille 9, 22767 Hamburg, Germany \\ ${ }^{3}$ Zentrum für Marine Tropenökologie, Universität Bremen, Fahrenheitstr. 6, 28359 Bremen, Germany
}

\begin{abstract}
Baseline respiration and spontaneous activity were determined simultaneously for 6 specimens of tropical scorpionfishes, belonging to 2 different genera: Scorpaenopsis oxycephalus and $S$. diabolus (false stonefish) and Parascorpaena sp. and P. aurita. The experiments were conducted in an intermittent-flow respirometer at $24^{\circ} \mathrm{C}$, at ambient light regime $(12 \mathrm{~h}$ dark: $12 \mathrm{~h}$ light) and salinity $(\mathrm{S}=32)$. Permanent measurements of fish activity by an infrared video system (number of movements) and oxygen consumption were coupled allowing the calculation of a standard oxygen consumption (SOC) rate. The experimental set-up allowed quantification of spontaneous activity. Relative SOC values varied between $32.3 \mathrm{mg} \mathrm{O}_{2} \mathrm{~h}^{-1} \mathrm{~kg}^{-1}$ wet mass (wm) for a large $S$. oxycephalus $(82 \mathrm{~g}$ $\mathrm{WM}$ ) and $68.9 \mathrm{mg} \mathrm{O}_{2} \mathrm{~h}^{-1} \mathrm{~kg}^{-1} \mathrm{WM}$ for the smallest investigated specimen, a $P$. aurita (16 $\left.\mathrm{g} \mathrm{WM}\right)$. The latter also showed the highest spontaneous activity rate (mean 98 movements $\mathrm{h}^{-1}$; max.: $870 \mathrm{~h}^{-1}$ ), while the values for the most sluggish individual did not exceed $24.6 \mathrm{~h}^{-1}$ (mean) and $480 \mathrm{~h}^{-1}$ (max.), respectively. Absolute $\mathrm{SOC}$ for a standard mass of $50 \mathrm{~g}$ was calculated to be $2.0 \mathrm{mg} \mathrm{O}_{2} \mathrm{~h}^{-1}$, using a wet mass versus oxygen consumption relationship of SOC $\left(\mathrm{mg} \mathrm{O}_{2} \mathrm{~h}^{-1}\right)=0.26 \times \mathrm{WM}(\mathrm{g})^{0.527}$. The tropical scorpionfish investigated are some of the most sluggish fish found on coral reefs, with activity levels (means and variance) similar to that of boreal or polar scorpaenids (e.g. sculpins). In this respect, there was no indication for any specific adaptation to temperature. Baseline oxygen consumption values of the fish in this study were the lowest recorded for marine tropical species, and a first rough comparison of the resting metabolism of scorpaenid fish over a wide range of environmental temperatures might indicate a reduced thermal sensitivity of the tropical fish investigated.
\end{abstract}

KEY WORDS: Respiration · Standard oxygen consumption · Spontaneous activity · Coral reefs · Scorpionfishes $\cdot$ Scorpaenidae

\section{INTRODUCTION}

Baseline metabolism is the minimum metabolic rate that a fish requires in order to maintain the physiological systems needed for survival. By definition, this minimum rate excludes any kind of internal or external work, even digestion, and all movements, except the ventilation of

*E-mail: czimmermann@ipoe.uni-kiel.de the gills for respiration. The common method to estimate baseline metabolism is to measure or calculate a standard oxygen consumption (SOC) rate.

Measurements of SOC have been made since the beginning of this century for many species of fish (e.g. Krogh 1914, Holeton 1972, 1980, Macdonald et al. 1987), with the purpose of estimating metabolism, energy requirements and activity level. A number of factors affect the oxygen demand of fish. Aside from the influence of the apparatus and methodology ap- 
plied and the size of the fish, the foremost factors are temperature, availability of oxygen, and the mode of life of the fish (Holeton 1980), particularly its spontaneous activity. In earlier studies different approaches were tried, while the methods were further developed and improved. Most papers, however, focused on the influence of temperature, and other factors were neglected.

In recent publications, attention has been paid to the influence of activity on oxygen consumption by categorising fish loosely as sluggish, moderate or active species (Saint-Paul et al. 1988, Johnston et al. 1991, Johnston \& Battram 1993), without defining activity quantitatively. As a consequence, the activity of active fish was likely underestimated, and the SOC overestimated. In addition, most of the polar species that were investigated were sluggish, and most of the tropical fish were rather active. A latitudinal comparison of fish metabolism was therefore likely to be biased and was rather more affected by the different modes of life of the species compared than by temperature.

Inclusion of quantitative measurements of fish activity should be a prerequisite for interspecies comparisons of oxygen consumption (Clarke 1991). Ideally, the influence of temperature on fish metabolism should include a latitudinal comparison using the same method on fish with comparative modes of life adapted to ambient temperature conditions.

The aims of the present study were therefore: (1) to quantify spontaneous activity and oxygen consumption in tropical fish of the family Scorpaenidae; (2) to find species or taxonomic groups in other climates which exhibit the same level of activity and thus the same mode of life; (3) to conduct a preliminary comparison of standard oxygen consumption over a wider range of temperatures and to estimate the thermal sensitivity of resting metabolism.

For this study, we choose specimens of the genera Scorpaenopsis and Parascorpaena, as they belong to the most sluggish fish to be found on coral reefs, and we therefore expected their oxygen consumption to be low. This eases the comparison with ecological equivalents in boreal and polar climates, where data from rather sluggish fish are available.

\section{MATERIALS AND METHODS}

Materials and experimental set-up. Experiments were conducted at the Fisheries Faculty's laboratory at Bung Hatta University, Padang, West Sumatra, Indonesia, during March 1997. Six tropical scorpionfishes were used for this investigation, belonging to 2 different genera: Scorpaenopsis oxycephalus (n = 3), $S$. diabolus ( $\mathrm{n}=1$, false stonefish), Parascorpaena sp. $(\mathrm{n}=1)$ and $P$. aurita $(\mathrm{n}=1)$. Species were identified by J.E. Randall, Bishop Museum, Hawaii, by means of live material and slides. For a review and key of the different scorpaenid species see Smith (1957). Table 1 provides wet mass of all animals used and experimental conditions. Fish were caught with hand nets by divers, on the coral reefs and gravel slopes of the Padang Islands, Indian Ocean (approximately $01^{\circ} \mathrm{S}, 100^{\circ} \mathrm{E}$ ), from 10 to $24 \mathrm{~m}$ water depth ( $\mathrm{T}$ at depth approximately 22 to $25^{\circ} \mathrm{C}$ ). They were transferred to the Faculty's air conditioned aquarium in aerated boxes, and kept there in large tanks (1300 l) at approximately $24^{\circ} \mathrm{C}$, in an ambient light regime (12 $\mathrm{h}$ dim light:12 $\mathrm{h}$ dark) in natural seawater $(S=32)$. The tanks were equipped with standard aquarium filters and pumps (Eheim/ Deizisau). Fish were allowed to recover from the stress of capture and transport and to acclimate to the experimental conditions for about 3 to $8 \mathrm{wk}_{\text {; }}$ feeding was stopped 7 to $12 \mathrm{~d}$ prior to transferring them to the respirometer. Experiments started within $1 \mathrm{~h}$ after transfer to the respiration chamber. Fish were kept in the chamber for the entire duration of the experiment (37 to $98 \mathrm{~h}$ ).

Table 1. Experimental conditions: experiment, species name, wet mass of the animal, total duration of the experiment, temperature (minimal, maximal, maximum change, mean). Notes: ${ }^{1} 60.5 \mathrm{~h}$ and ${ }^{2} 84 \mathrm{~h}$ total experiment duration (37.5 and $24 \mathrm{~h}$ of valid recordings, respectively, were lost due to power failure)

\begin{tabular}{|c|c|c|c|c|c|c|c|c|}
\hline \multirow{2}{*}{ Expt } & \multirow{2}{*}{ Species } & \multirow{2}{*}{$\begin{array}{l}\text { Wet mass } \\
(\mathrm{g})\end{array}$} & \multirow{2}{*}{$\begin{array}{c}\text { Expt } \\
\text { duration (h) }\end{array}$} & \multicolumn{4}{|c|}{ - Temperature $\left({ }^{\circ} \mathrm{C}\right)$} & \multirow[t]{2}{*}{ Note } \\
\hline & & & & Min. & Max. & $\Delta$ Temp. & Mean & \\
\hline Para1 & Parascorpaena sp. & 32 & 23.00 & 23.6 & 24.7 & 1.1 & 24.1 & 1 \\
\hline Scorp1 & Scorpaenopsis oxycephalus & 57 & 94.25 & 24.0 & 26.5 & 2.5 & 25.5 & \\
\hline Scorp2 & Scorpaenopsis diabolus & 85 & 62.00 & 23.1 & 25.7 & 2.6 & 24.4 & \\
\hline Scorp3 & Scorpaenopsis oxycephalus & 35 & 97.75 & 22.5 & 25.2 & 2.7 & 24.0 & \\
\hline Scorp4 & Parascorpaena aurita & 16 & 37.25 & 23.9 & 26.5 & 2.6 & 24.9 & \\
\hline Scorp5 & Scorpaenopsis oxycephalus & 82 & 60.00 & 22.9 & 25.5 & 2.6 & 24.0 & 2 \\
\hline$\sum$ & & & 351 & 22.5 & 26.5 & 4.0 & & \\
\hline Mean & & 72 & 70 & 23.3 & 25.9 & 2.6 & 24.6 & \\
\hline
\end{tabular}




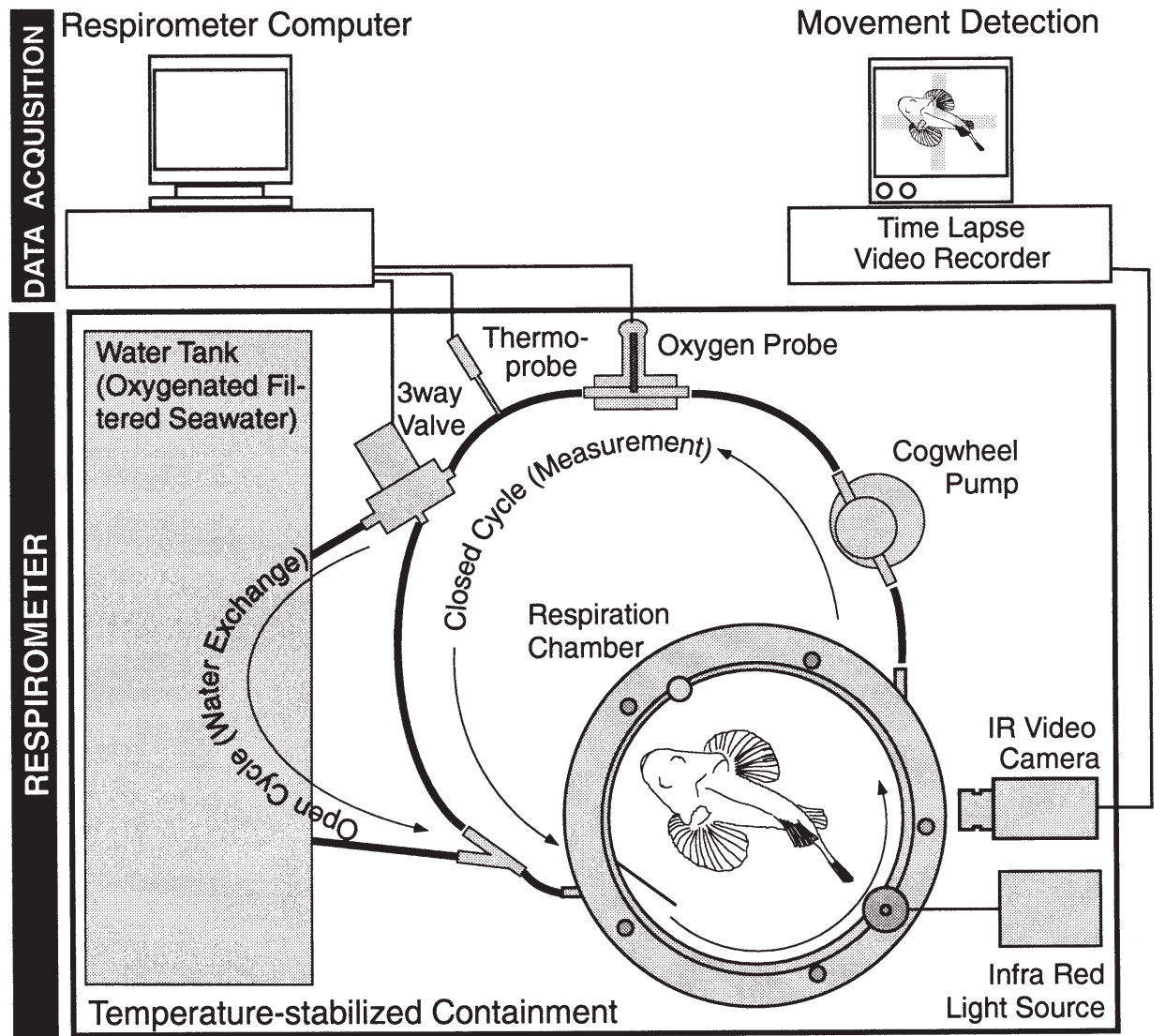

Fig. 1. Intermittent flow respirometer (schematic view from above) with set-up for movement detection. Modified from Zimmermann \& Hubold (1998)

For synchronous recording of oxygen consumption, spontaneous activity and other standard variables (e.g. temperature) during the experiment, a modified intermittent flow respirometer (Forstner 1983, Steffensen et al. 1984, Steffensen 1989, Zimmermann \& Hubold 1998) was used (Fig. 1). Single fish were kept in circular, flat-bottom acrylic respiration chambers, large enough to allow spontaneous movements (inner diameter: $190 \mathrm{~mm}$; volume: $2270 \mathrm{ml}$ ). The system was filled with sterile- filtered (Sartobran $0.2 \mu \mathrm{m}$ ), natural seawater. Water was sub-sampled continuously and pulsefree with a Teflon cogwheel pump (Ismatec/Zürich pump head, customised Faulhaber/Munich engine, magnetically coupled) at a constant flow rate. Oxygen content and temperature were automatically determined by a computer-controlled polarographic oxygen probe (Eschweiler/Kiel) and a customised PT100thermo-element (Driessen \& Kern/Bad Bramstedt) respectively, and the water was recirculated to the chamber (closed measurement cycle, $2500 \mathrm{ml}$ total volume). When $\mathrm{O}_{2}$ saturation dropped below $89 \%$, the water was exchanged with oxygenated seawater from a separate tank (open cycle, by means of an electronic 3-way valve, Nortec/Kiel). The software running on the respirometer steering and control unit (IBP/Hannover) was developed by Dr. Florian Schulz, Kiel. It collects about 10000 pairs of oxygen/temperature values per minute, eliminates obvious outliers (max. 1\% of the data), calculates the oxygen saturation (according to the formula by Weiss 1970) and consumption over 2 min intervals and controls the 3-way valve. The whole set-up of the respirometer, the function of the software and all initial settings were modified iteratively following the results of some 100 experimental trials over the course of $10 \mathrm{yr}$, always aiming at reducing the stress for the animal in the respirometer, on the one hand, and gaining the highest temporal resolution on the other (Zimmermann 1997).

Between trials, the whole system was detached, thoroughly cleaned and sterilised with $98 \%$ Ethanol (and electrode cleaner, respectively), and worn-out Tygoon tubing was replaced. After refilling, initial blank respiration was measured over the course of at least $3 h_{\text {; }}$ it was never significantly different from 0 .

The activity of the fish was monitored continuously (over about $90 \%$ of each experiment's runtime) with an infra-red (IR) video camera (Scharpf/Frankfurt CCD500S) under IR illumination (LED) and recorded with a 
time-lapse recorder (Panasonic AG6720E, 16-fold time lapse $=1.56$ frames $\mathrm{s}^{-1}$ ). Recordings were evaluated manually, with an exact runtime assigned to every single fish movement (Zimmermann 1997). One movement was defined as the change of position of $>50 \%$ of the animal's body, regardless of the absolute distance covered. The counts of individual movements were summarised ('binned') for 2 min intervals. In addition, mean and maximum movement rates (projected to $1 \mathrm{~h}$ ), their ratio as a measure for 'mode of life' (Zimmermann \& Hubold 1998; see 'Discussion') and elapsed time between two single movements ('pauses') were determined. Again, numerous early trials were conducted to assess the reliability of the evaluation and to decide on the best evaluation strategy.

Data processing. Raw data were processed following standard procedures (see Zimmermann 1997 for more details): they were corrected for background microbial respiration (blanks), and activity and respiration were synchronised to account for the delay of the respiration signal using standard mathematical procedures (best fit of the regression). Finally, a linear regression between activity (in terms of movements per unit time, usually $2 \mathrm{~min}$ ) and respiration (for the same interval) was computed, and SOC rate was determined by extrapolation to zero movement, using a procedure similar to those of Spoor (1946), Fry (1947) and Beamish \& Mookherjii (1964). Finally, a regression between absolute SOC and wet mass (WM) over all experiments was computed (absolute $\mathrm{SOC}=a \mathrm{WM}^{b}$, Winberg 1956) to calculate baseline respiration for a standard mass of 50 or $100 \mathrm{~g}$.

Due to tropics-specific problems (i.e. partial air conditioner failures in the laboratory), correction procedures had to be applied to parts of some data sets. During 3 experiments (see Table 3 ), the temperature in the respirometer could not be kept constant and varied by a maximum of $2^{\circ} \mathrm{C}$ within $24 \mathrm{~h}$. For the periods affected, respiration values were standardised to the mean temperature by a factor calculated from the regression of temperature and respiration after exclusion of obvious phases of activity. Further, a progressive blank correction (increasing with runtime) had to be applied for experiment Scorp2 instead of the standard blank reduction (see 'Discussion').

\section{RESULTS}

\section{Activity}

The 6 respiration experiments evaluated lasted for a total of $351 \mathrm{~h}$ (up to almost $98 \mathrm{~h}$ experiment ${ }^{-1}$ ). From video recordings, more than 13700 movements were counted. Large individual differences in respiration as well as in activity were found between the specimens (Table 2). The most active individual was Parascorpaena aurita, the smallest fish investigated. It showed a mean movement rate of $98.1 \mathrm{~h}^{-1}$ and a maximum of $870 \mathrm{~h}^{-1}$, which is almost 5 times (and 1.7 times, respectively) the values found for the most sluggish animal, a Scorpaenopsis oxycephalus (Scorp3). The mean movement rate for all specimens was about $48 \pm 30( \pm \mathrm{SD})$ $\mathrm{h}^{-1}$, the median rate $42 \mathrm{~h}^{-1}$. The ratio between maximum and mean movement rate, which might be a measure for the 'mode of life' of a fish (Zimmermann \& Hubold 1998), was lowest (8.9) for the most active and smallest fish (Scorp4) and highest (25.4) for a mediumsized $S$. oxycephalus (Scorp3); the mean for all fishes was $16.7 \pm 5.7( \pm \mathrm{SD})$. The mean duration of phases without activity (pauses) was inversely correlated with the movement rate: this value was $36 \mathrm{~s}$ for $P$. aurita and 2 to $3 \mathrm{~min}$ for the sluggish $S$. oxycephalus. No clear trend was found for the maximum duration of pauses: on 1 occasion $P$. aurita did not move for 1 h 16 min, while the longest pauses of the 3 specimens of $S$. oxycephalus varied between $46 \mathrm{~min}$ and $1 \mathrm{~h} 12 \mathrm{~min}$.

\section{Respiration}

Absolute SOC was calculated to be between 1.1 and $5.5 \mathrm{mg} \mathrm{O} \mathrm{O}^{-1}$, mainly depending on the wet mass of the fish (Table 3 ). For the estimation of baseline respi-

Table 2. Results of the experiments: activity. Experiment, species name, movement rate (maximum, mean and ratio between max. and mean), 'pauses' (duration of phases between 2 movements, max. and mean) and total number of recorded movements during the experiment

\begin{tabular}{|c|c|c|c|c|c|c|c|}
\hline \multirow[t]{2}{*}{ Expt } & \multirow[t]{2}{*}{ Species } & \multicolumn{3}{|c|}{ Movement rate $\left(\mathrm{h}^{-1}\right)$} & \multirow{2}{*}{$\begin{array}{l}\text { Pause max. } \\
\text { (h:min:s) }\end{array}$} & \multirow{2}{*}{$\begin{array}{l}\text { Pause mean } \\
\text { (min:s) }\end{array}$} & \multirow{2}{*}{$\begin{array}{l}\text { No. of } \\
\text { moves }\end{array}$} \\
\hline & & Max. & Mean & Max./mean & & & \\
\hline Para1 & Parascorpaena sp. & 750 & 58.5 & 12.8 & $0: 40: 42$ & 01:01 & 1350 \\
\hline Scorp1 & Scorpaenopsis oxycephalus & 480 & 24.6 & 19.5 & $0: 47: 34$ & $02: 27$ & 2201 \\
\hline Scorp2 & Scorpaenopsis diabolus & 750 & 55.2 & 13.6 & 1:03:17 & 01:04 & 3424 \\
\hline Scorp3 & Scorpaenopsis oxycephalus & 510 & 20.1 & 25.4 & $0: 46: 15$ & $02: 57$ & 1451 \\
\hline Scorp4 & Parascorpaena aurita & 870 & 98.1 & 8.9 & $1: 16: 24$ & $00: 36$ & 3616 \\
\hline Scorp5 & Scorpaenopsis oxycephalus & 630 & 29.1 & 21.6 & 1:12:08 & 02:04 & 1729 \\
\hline
\end{tabular}


Table 3. Results of the experiments: respiration. Experiment, species name, absolute calculated standard oxygen consumption (cSOC), relative calculated SOC with upper and lower limits of the $95 \%$ confidence interval, adjusted regression coefficient for the regression fitted to respiration versus activity and number of data points used for this calculation. Notes: ${ }^{1}$ respiration standardised to mean temperature to account for temperature deviation during the experiment; ${ }^{2}$ progressive blank-correction conducted. For more details see 'Material and methods' section

\begin{tabular}{|c|c|c|c|c|c|c|c|c|}
\hline Expt & Species & $\begin{array}{c}\text { Absolute } \\
\text { CSOC } \\
\left(\mathrm{mg} \mathrm{O}_{2} \mathrm{~h}^{-1}\right)\end{array}$ & $\begin{array}{c}\text { Relative } \\
\text { cSOC } \\
\left(\mathrm{mg} \mathrm{O}_{2} \mathrm{~h}^{-1} \mathrm{~kg}^{-1} \mathrm{WM}\right)\end{array}$ & \multicolumn{2}{|c|}{$\begin{array}{c}95 \% \text { confidence } \\
\text { interval }\end{array}$} & Adjusted $\mathrm{R}^{2}$ & $\begin{array}{l}\text { Points used } \\
\text { for regression }\end{array}$ & Note \\
\hline Para1 & Parascorpaena sp. & 1.9 & 60.3 & 59.3 & 61.4 & 0.61 & 408 & \\
\hline Scorp1 & Scorpaenopsis oxycephalus & 2.2 & 38.7 & 38.2 & 39.2 & 0.32 & 2630 & 1 \\
\hline Scorp2 & Scorpaenopsis diabolus & 5.5 & 64.9 & 64.3 & 65.5 & 0.61 & 1482 & 2 \\
\hline Scorp3 & Scorpaenopsis oxycephalus & 1.4 & 41.0 & 40.7 & 41.3 & 0.23 & 1924 & 1 \\
\hline Scorp4 & Parascorpaena aurita & 1.1 & 68.9 & 67.7 & 70.1 & 0.72 & 793 & \\
\hline Scorp5 & Scorpaenopsis oxycephalus & 2.6 & 32.3 & 31.9 & 32.8 & 0.17 & 1636 & 1 \\
\hline \multirow{2}{*}{\multicolumn{2}{|c|}{$\begin{array}{l}50 \mathrm{~g} \text { fish } \\
100 \mathrm{~g} \text { fish }\end{array}$}} & 2.0 & 40.9 & \multirow{2}{*}{\multicolumn{5}{|c|}{$\begin{array}{l}\text { Calculated from WM/absolute SOC regression } \\
\text { Calculated from WM/absolute SOC regression }\end{array}$}} \\
\hline & & 2.9 & 29.4 & & & & & \\
\hline
\end{tabular}

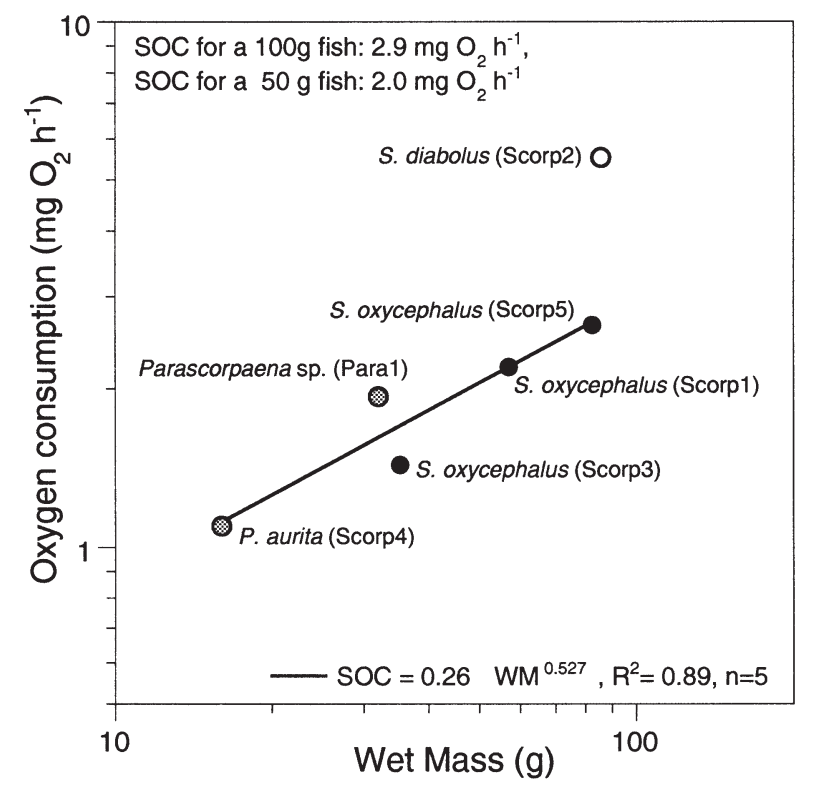

Fig 2. Wet mass versus absolute calculated SOC for the different experiments. Filled circles were used to calculate the regression. Full species' name see Table 1

ration of an individual weighing 50 or $100 \mathrm{~g}$, an absolute oxygen consumption-mass relationship was computed (Fig. 2). Apart from Scorpaenopsis diabolus (Scorp2), all calculated SOC values were used for this first approximation, although they belong to different species with possible small differences in their life styles (see 'Discussion'). The exponent $b=0.52$ indicated a strong inverse mass dependency of respiration. Relative SOC (mass standardised) varied between $32 \pm$ $0.2 \mathrm{mg} \mathrm{O} \mathrm{h}^{-1} \mathrm{~kg}^{-1} \mathrm{WM}$ ( $\pm \mathrm{SE}$ ) for $S$. oxycephalus (Scorp5) and $69 \pm 0.6 \mathrm{mg} \mathrm{O}_{2} \mathrm{~h}^{-1} \mathrm{~kg}^{-1} \mathrm{WM}$ for the small Parascorpaena aurita (Scorp4). The mean SOC for all individuals investigated was $51 \pm 15.5 \mathrm{mg} \mathrm{O}_{2} \mathrm{~h}^{-1} \mathrm{~kg}^{-1}$
WM $( \pm \mathrm{SD})$. The slope of the regression curves between activity and respiration, which is a rough measure for the oxygen requirements of a single move, was calculated to be between 0.11 and $0.27 \mathrm{mg} \mathrm{O}_{2} \mathrm{~kg}^{-1} \mathrm{WM}$ movement $^{-1}$ (mean \pm SD: $\left.0.18 \pm 0.06\right)$.

As examples, Fig. 3 shows the course of a typical experiment, and Fig. 4 shows 2 regressions between activity and respiration.

All experiments were statistically tested for any nocturnal rhythm. At a first glance, most of the fish showed higher activity (up to 3.1-fold increase) and respiration (up to 1.5-fold) during night. However, we felt that the duration of the trials was still too short for a more detailed analysis.

\section{DISCUSSION}

Fishes of the family Scorpaenidae (cottids, sculpins) are nearly ubiquitous in the world's oceans, from northern polar to tropical regions, and from shallow brackish to deep sea habitats. Only a few species are considered active, with a holopelagic lifestyle and pelagic larvae (e.g. the commercially important redfishes Sebastes sp.), while most of them are sluggish and strictly benthic. These animals have acquired a variety of adaptations to the benthic habitat, such as the reduction of the swim-bladder and the development of benthic larvae (Arctic Artediellus sp., Dorrien 1996). To prevent predation, a variety of defense mechanisms including camouflage, disruptive and/or signal colourations, armor plates and venomous spines, have evolved (among these mechanisms is the strongest poison known from fishes, of the tropical stonefish Synanceia verrucosa, Endean 1961). These adaptations enable scorpaenids to manage without high escape velocities and to evolve an extremely slug- 


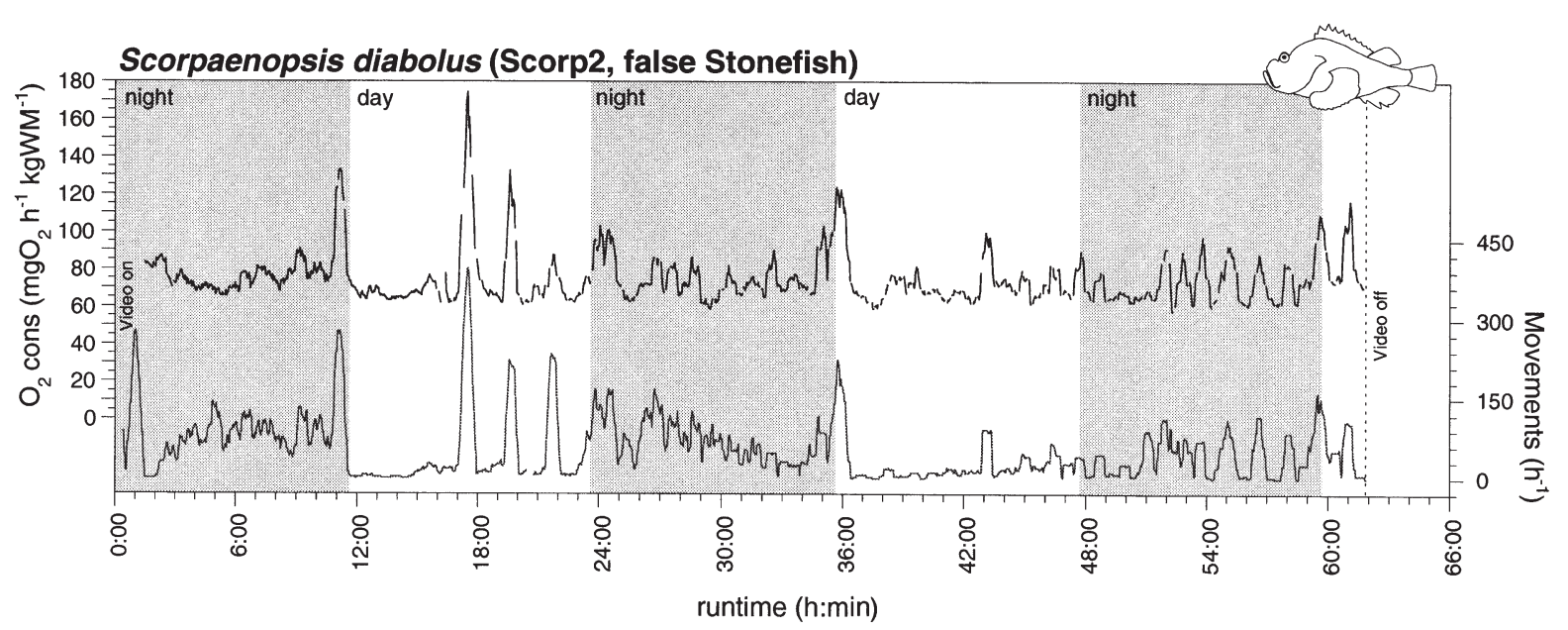

Fig. 3. Scorpaenopsis diabolus (Scorp2, false stonefish). Respiration (upper line) and spontaneous activity (lower line) versus runtime of the experiment. Both parameters are smoothed over 15 values (30 min) and synchronised. Night time (18:45 to 06:45 h) is indicated with grey shading
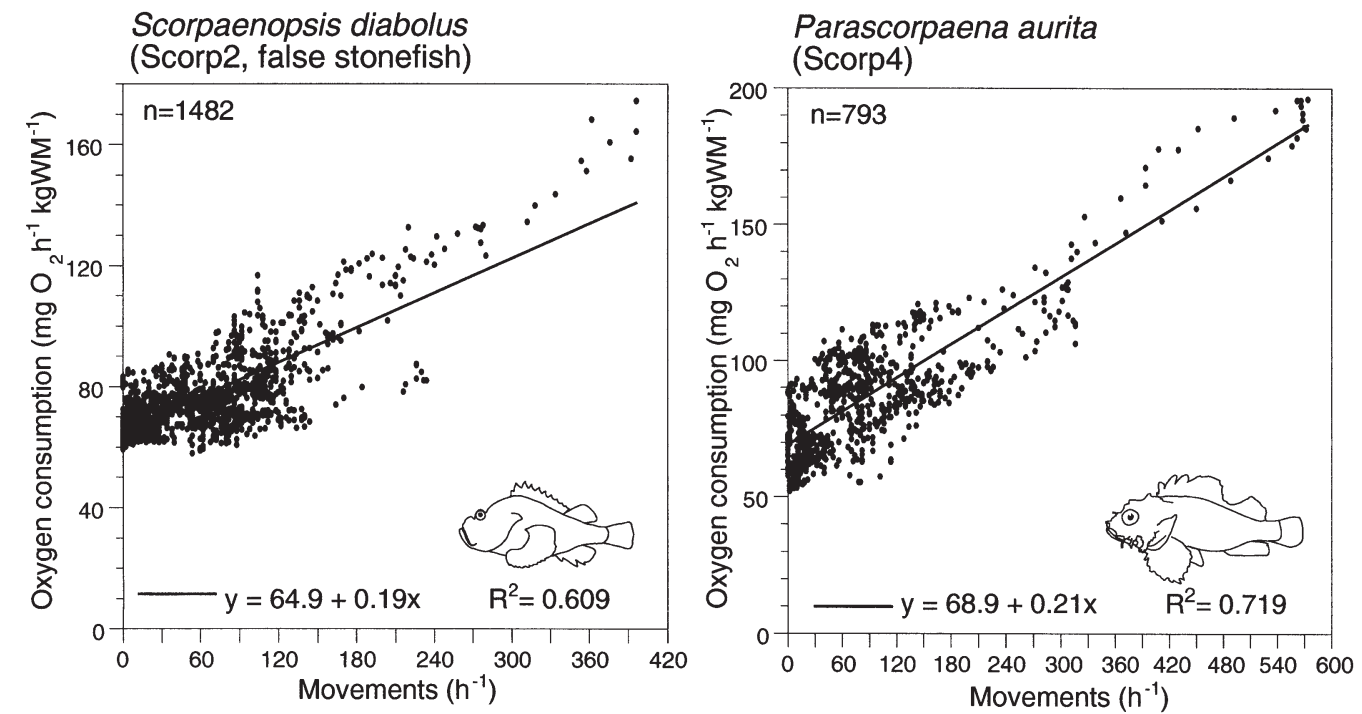

Fig. 4. Scorpaenopsis diabolus (Scorp2, false stonefish) (left) and Parascorpaena aurita (Scorp4) (right) Linear regression for respiration versus activity, used for the calculation of the standard oxygen consumption (SOC, the intercept)

gish mode of life. This lifestyle, the occurrence of scorpaenid species in virtually all climatic zones and the lack of extensive migration make scorpaenids an ideal group for studying latitudinal effects on physiology and behaviour, including baseline metabolism and activity.

\section{Methodology}

The baseline metabolism depends on various factors. Among the most important ones is activity. This factor can be excluded when using an experimental set-up as presented here. The permanent determination and quantification of spontaneous activity allows extrapolation of respiration to zero activity - at least for rather sluggish fish, where individual movements could be clearly separated. With this approach, determination of SOC is possible even when the fish display only short phases of inactivity. A standardisation to SOC is a prerequisite to compare the metabolism of active and inactive fish, as well as fish from different climates. Another advantage of this method is that the acclimation period (which could be longer than $24 \mathrm{~h}$ for some species) can be used for SOC determination: for the fish investigated here, $>90 \%$ of the initial increase of 
oxygen consumption could be attributed to enhanced activity. Recording respiration and activity during this phase would therefore improve the established relationship between those parameters.

Stress is the second important factor. We carefully tried to reduce all kinds of stress during handling the animals and conducting the experiments. As we were looking for lowest possible SOCs, we chose a 'conservative' approach for evaluating the data: any assumptions that were made lead to higher respiration rates; in fact there is some probability that actual values are even lower than the ones presented here. Crucial points which could not be controlled completely and which may have resulted in an elevated activity and/or metabolism could be:

- the presence of specific dynamic action (SDA), the energy needed to digest. In contrast to common belief, stomach evacuation rates proved to be rather low. While Crawford (1978) reported complete gut evacuation rates for boreal scorpeanids to be $<6 \mathrm{~d}$, we found faeces even $14 \mathrm{~d}$ after the last meal in the aquarium. Food retention time for these tropical fishes might be much longer than believed so far, and they might be capable of surviving extended periods of scarce food availability by reducing their metabolism as well.

- the lack of substrate in the respiration chamber: Scorp4, the smallest investigated specimen, was never observed to sit in a stretched position on the sandy bottom of the aquarium, but tried to attach to small coral pieces to hide (Fig. 5). Scorp2, the false stonefish, was found partly burrowed in fine coral rubble. These 2 animals might have been especially sensitive to the lack of substrate during the measurements, and possibly showed a higher activity than in the field.

The experiment Scorp2 showed another peculiarity: the blank (microbial) respiration was unusually high (it resulted in up to $50 \%$ of the total respiration) and, unlike other experiments, increased continuously over the course of the experiment. The increase could not be attributed to a drift of the probe, as it proved to be absolutely stable after removal of the animal. It is most likely that the extremely structured surface of the animal houses a larger number of micro-organisms than the skin of the other scorpaenids, and that these are introduced into the respiration chamber together with the animal. As mentioned earlier, a progressive blank correction was conducted to account for bacterial growth in the system. However, the initial respiration attributable to bacteria attached to the fish's skin was hardly quantifiable, but surely significant. This would result in an overestimation of the oxygen consumption; we therefore decided to exclude this single experiment from the calculation of the mass dependency of absolute respiration (Fig. 2).

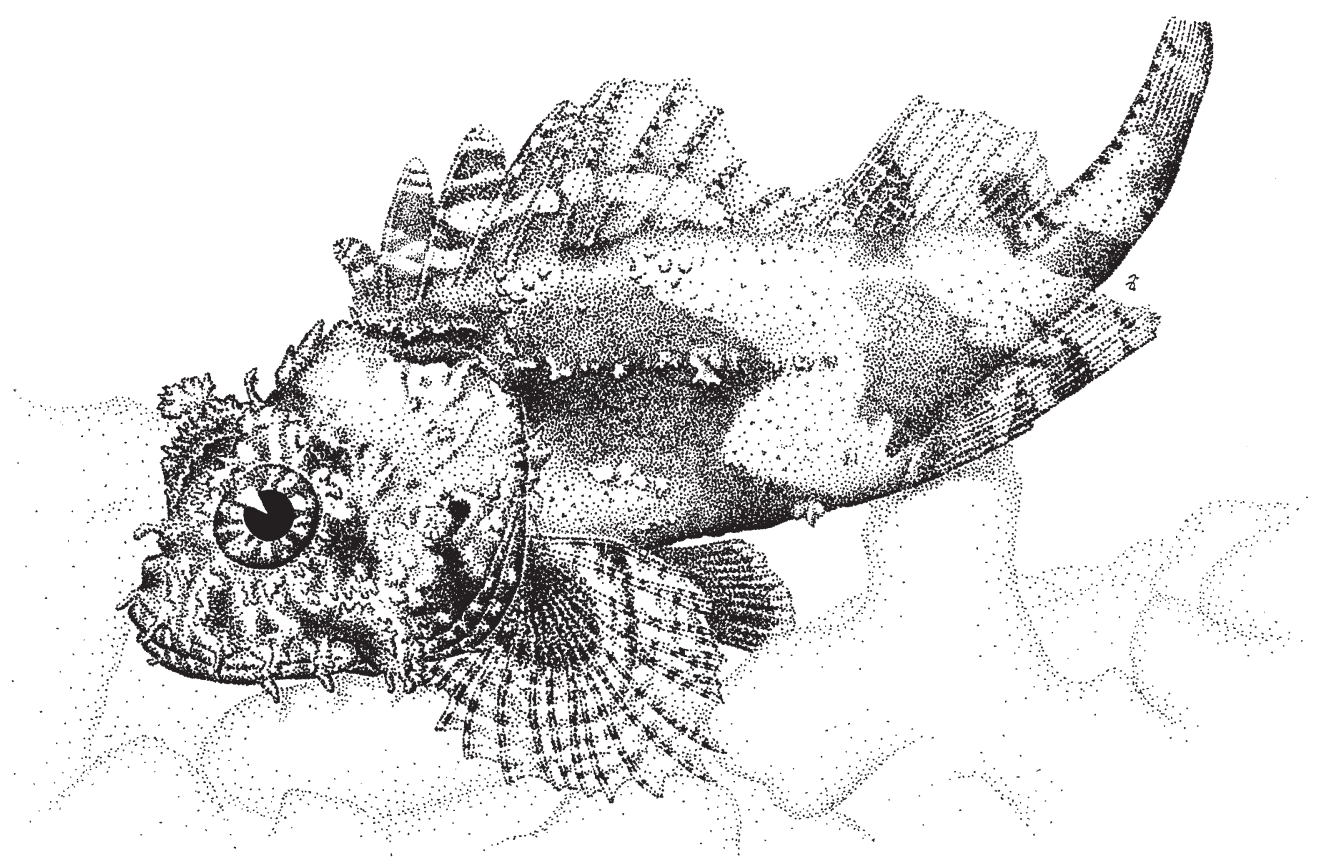

Fig. 5. Habitus of a Parascorpaena aurita (Scorp4, ca $5 \mathrm{~cm}$ standard length) on coral rubble. This specimen shows a position typical for all individuals investigated: the caudal fin is folded and bent upwards, the pectoral fins are spread. All animals were found on coral rubble of reef flats or slopes, preferably sitting elevated on smaller coral blocks, in 5 to $24 \mathrm{~m}$ depth. In the aquarium, they were observed to be typical ambush predators, preying on living fish from a close distance (without leaving their position), and being able to survive extended periods of lack of food: some specimens did not feed for $>3 \mathrm{wk}$ after capture 


\section{Activity}

With this work we have tried to quantify for the first time the activity of tropical fish kept in a respirometer; this is a prerequisite to define their activity beyond generalised statements like 'sluggish' or 'active'. From earlier investigations on polar and temperate scorpaenids (e.g. Endean 1961, Grobecker 1983, Panten 1995, Zimmermann 1997) and diving observations, it was expected that the scorpaenids chosen for this investigation would be among the most sluggish fish to be found in coral reefs. However, the scorpaenids investigated showed a surprisingly wide range of activity. This mainly reflects individual differences and is hardly attributable to different species or to body mass. It has been clearly demonstrated that spontaneous activity has to be measured for every single fish and that generalisations, even for 1 species (e.g. Johnston et al. 1991), are of limited use. One might therefore question whether it is suitable to treat animals belonging to different, but closely related, species as one, as done here; however, the error introduced by doing so is, in our opinion, not larger than the error caused by the variance within a single species.

As the species investigated were expected to be very sluggish, it was surprising that the longest phase of inactivity detected in the course of the experiments was not longer than $1 \mathrm{~h} 16 \mathrm{~min}$. The mean duration of pauses was shorter than $3 \mathrm{~min}$, which is in clear contrast to the findings of Johnston et al. (1991). They proposed that the tropical hawkfish Parachirrhites sp., which is clearly more active in the field, regularly showed phases of inactivity of longer than $30 \mathrm{~min}$. These periods were then taken to determine the SOC. If the fish showed some unrecognised spontaneous activity, the SOC would be overestimated. Generally, it is obvious that the determination of an SOC without simultaneous and permanent recording of activity would only be possible for extremely sluggish fish.

The method used here for determining spontaneous activity is limited to bottom-living fish kept in respirometers which have sufficient, but not too much, space available for spontaneous movements, because only the movement count is quantified. No estimation can be given about the distance covered per single move or the energy requirement for swimming a specific distance. A comparison of the activity of the investigated animals with other fish is therefore especially useful when the results are achieved by means of the same method. This was done in a previous work on polar fish (Zimmermann 1997), covering a wide range of activities, from active cryopelagic hunters (Boreogadus saida in the north and Pagothenia borchgrevinki in the south) to extremely sluggish sit-and-wait predators
(Antarctic Pogonophryne sp.; Table 4). Compared to these polar fishes, tropical scorpaenids show activity parameters similar to those of the arctic/boreal sculpin Myoxocephalus scorpius. The variability of all parameters was even larger for the Arctic animals, although they all belonged to a single species. These fishes, which showed no diurnal rhythm, did not display significantly shorter pauses than the investigated tropical scorpaenids. In contrast, there is strong evidence that the latter show a day/night rhythm, with activity peaks during night. This has already been shown for Mediterranean scorpaenids (Harmelin-Vivien et al. 1989), and suggested for tropical species of this family (on visual observation: Hobson 1972; on the basis of the distribution of visual pigments: Munz \& MacFarland 1973).

Zimmermann \& Hubold (1998) proposed use of the quotient between maximum and mean movement rate as a first quantitative parameter for characterising the mode of life of a species, with higher values pointing towards more sluggish life styles. Advantages of using this parameter are discussed extensively in the mentioned paper. The values calculated here for tropical species (about 9 to 25; Table 4) correspond well with the values determined for Arctic Myoxocephalus scorpius (6 to 33), showing again that the range of activity or modes of life is even wider in the Arctic sculpin. Further, the quotient is at the 'sluggish' end of all values available so far, but far from being extremely sluggish like Antarctic Pogonophryne sp. (31 to 135).

\section{Oxygen consumption: low latitudes}

Among coral reef fishes, it is most likely that the scorpaenids are situated at the lower end of the activity scale. For the SOC, one would therefore expect the lowest values ever recorded for tropical fish. This expectation is supported by the available literature (Table 5): The few available investigations on tropical marine fish reported SOCs or 'resting metabolic rates', that were 1.5- to 2.6-fold higher than those calculated in this work. As mentioned earlier, the comparison is hampered by the fact that no careful determination of spontaneous activity was conducted in the previous investigations; thus measurements may have included some activity and represented routine oxygen consumption rather than SOC. The aim of the studies by Johnston \& Battram (1993) and Johnston et al. (1991) was a comparison of fish with a similar lifestyle living at different temperatures. However, the authors defined 'similar lifestyle' only through rough generalisations like 'sedentary' or 'ambush predators'. 


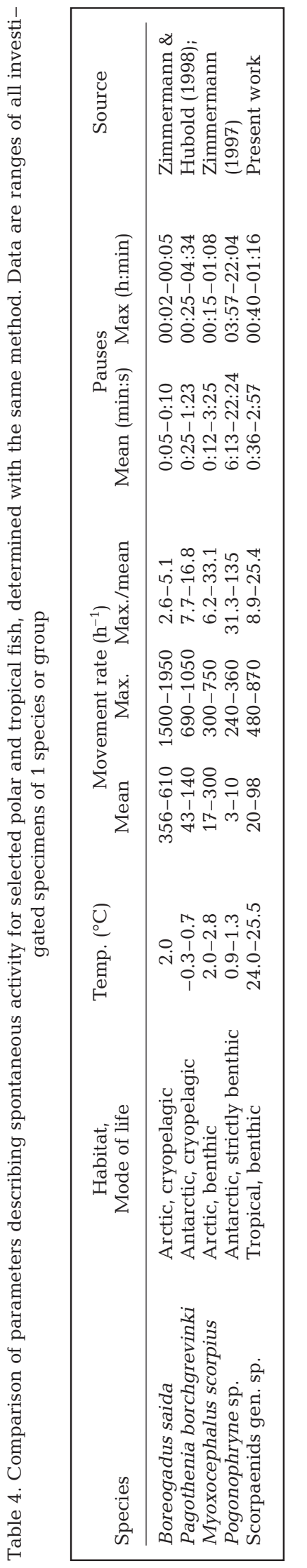

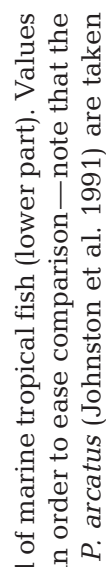

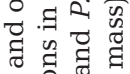

究.

它客这

象,

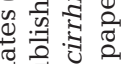

สี สำ

$\vec{f}$

यั山

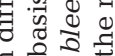

द 0 क

诘吉

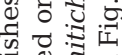

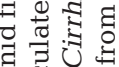

बृ

o

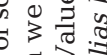

궁

룩원

要营

要焉

. .9

क웡

部菏

\& 35

훙요

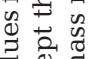

व

o

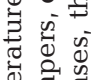

跴。

욤

论

)

घี

is

过

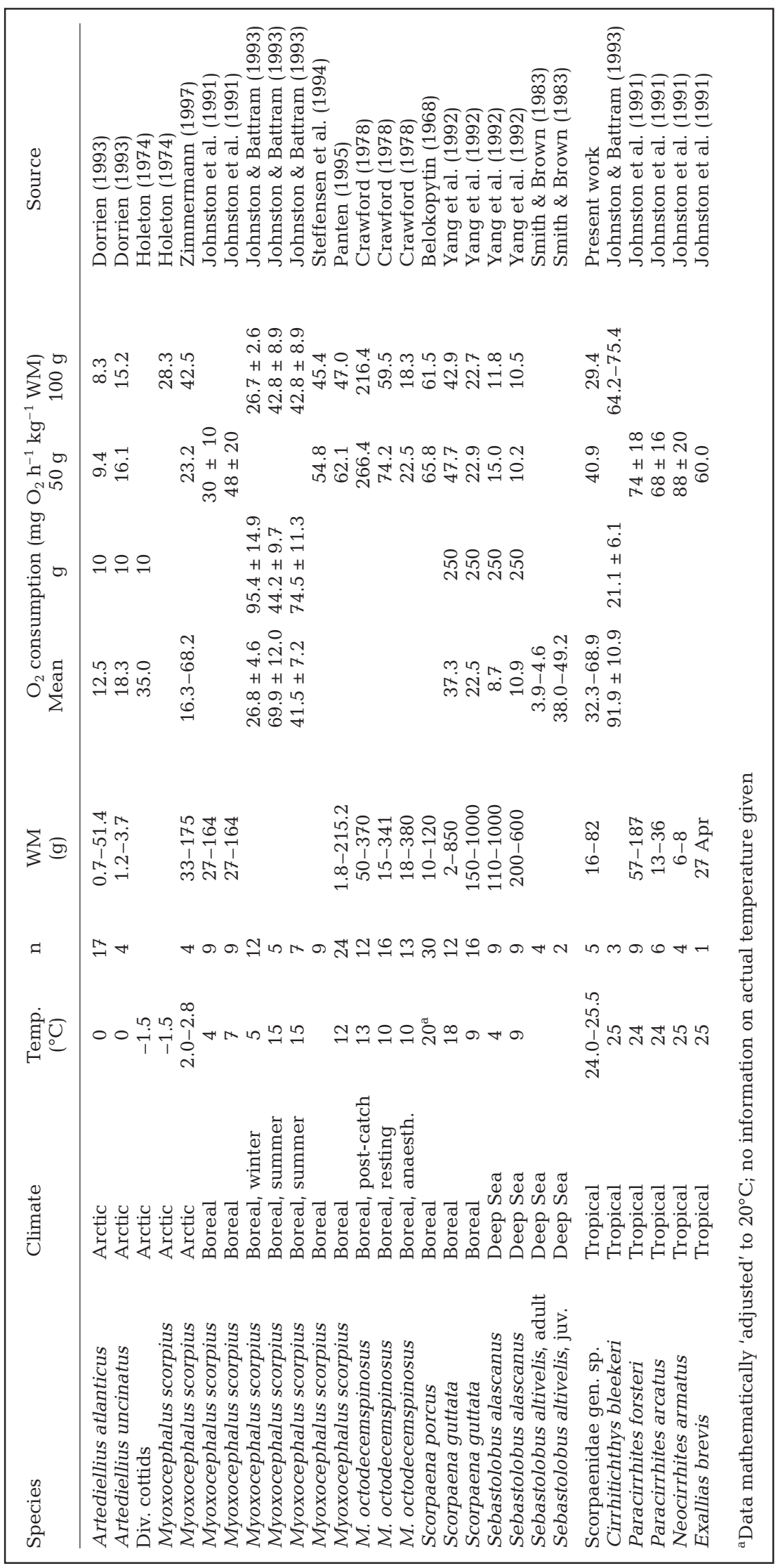




\section{Oxygen consumption: all latitudes}

For the determination of the influence of temperature on fish respiration, a comparison of scorpaenid fishes from different climates seems promising. Values from fishes examined at their regular environmental temperature, rather than being cooled or heated for a short time, are listed in Table 5. It is important to use only these values for comparison, as Clarke \& Johnston (1999) suggested that evolutionary temperature adaptation has produced a between-species relationship of temperature and resting metabolism that has a lower thermal sensitivity than is typical of within-species relationships. Conducting an extensive literature survey on fish respiration, the authors found a $Q_{10}$ of 2.4 for within-species acclimation studies, while the thermal sensitivity between species (animals measured at ambient temperatures, range 0 to $30^{\circ} \mathrm{C}$ ) was reduced to 1.83. Using only data for scorpaenids, we found a $Q_{10}$ of 1.65 (that means, the oxygen consumption and thus the food requirements for fuelling baseline metabolism, rises by 1.65 times when the temperature increases by $10^{\circ} \mathrm{C}$, Clarke \& Johnston 1999). If only the values collected with the method described here are taken into account (present work and Zimmermann 1997 , temperature range 0 to $25^{\circ} \mathrm{C}$ ), there is some evidence for an even further reduced thermal sensitivity. In one of their final conclusions, Clarke \& Johnston (1999) attributed the reduction of $Q_{10}$ to evolutionary mechanisms within taxonomic groups, while we believe that the mode of life is the driving factor in thermal sensitivity.

\section{Conclusions}

In this paper, it could be shown that the investigated tropical fish are typical scorpaenids, showing the same activity level and variability of activity as their Arctic and temperate relatives, the sculpins. This shows that spontaneous activity of a tropical fish can very well be as little as that of a polar fish.

A first rough comparison of the resting metabolism of members of this wide-spread family over a temperature range of 0 to $25^{\circ} \mathrm{C}$ indicates a reduced thermal sensitivity. In contrast to the activity, there might be evidence for specific physiological adaptations to temperature. However, a broader data basis would be needed to verify these findings. As the lower end of the possible activity range was not reached (as compared to polar fish), it would be promising to deliberately look for an even more sluggish fish from the tropics, even if it is a freshwater species. The lack of information on very inactive species is also evident for temperate environments, and a closer look at, e.g., agonids or trachinids seems promising. The careful measurement of such species, with the method described in this paper and with emphasis on the quantification of the spontaneous activity and mode of life, would most likely come up with a new record low for the standard oxygen consumption of fish in these climatic zones, and would ultimately allow the definition of an activity-independent respiration baseline over all temperature ranges.

Acknowledgements. This work was partly financed by the German Academic Exchange Service (DAAD) by means of a long-term lectureship to A.K. and a short-term lectureship to C.Z. The support of the staff of Bung Hatta University's fisheries faculty, Padang, of the captain and crew of the faculty vessel KM 'Faperi' and of Jack Randall (Hawaii) is gratefully acknowledged. Gerd Hubold and Cornelius Hammer (Hamburg), Dieter Piepenburg (Kiel) and 3 anonymous referees gave valuable comments on the manuscript.

\section{LITERATURE CITED}

Beamish FWH, Mookherjii PS (1964) Respiration of fishes with special emphasis on standard oxygen consumption. Can J Zool 42:161-175

Belokopytin Yu S (1968) Basal metabolic rate in some marine fishes. Probl Ichthyol 8:306-309

Clarke A (1991) What is cold adaptation and how should we measure it? Am Zool 31 (1):81-92

Clarke A, Johnston NM (1999) Scaling of metabolic rate with body mass and temperature in teleost fish. J Anim Ecol 68: 893-905

Crawford RE (1978) Different oxygen consumption rates by the longhorn sculpin Myoxocephalus octodecimspinosus in an apparatus designed for shipboard use. Mar Biol 44:377-381

Dorrien CF von (1993) Ökologie und Respiration ausgewählter arktischer Bodenfischarten. Ber Polarforsch 125:1-104 (in German)

Dorrien CF von (1996) Reproduction and larval ecology of the Arctic fish species Artediellus atlanticus (Cottidae). Polar Biol 16 (6):401-407

Endean R (1961) A study of the distribution, habitat, behaviour, venom apparatus, and venom of the stone-fish. Aust J Mar Freshw Res 12:177-190

Forstner H (1983) An automated multiple-chamber intermittent-flow respirometer. In: Gnaiger E, Forstner H (eds) Polarographic oxygen sensors. Springer, Berlin, p 111-126

Fry FEJ (1947) Effects of the environment on animal activity. Univ Tor Stud, Biol Ser 55:1-62

Grobecker DB (1983) The 'lie-in-wait' feeding mode of a cryptic teleost, Synanceia verrucosa. Environ Biol Fishes 8 (3/4):191-202

Harmelin-Vivien ML, Kaim-Malka RA, Ledoyer M, JacobAbraham SS (1989) Food partitioning among scorpaenid fishes in Mediterranean seagrass beds. J Fish Biol 34(5): 715-734

Hobson ES (1972) Activity of Hawaiian reef fishes during the evening and morning transitions between daylight and darkness. Fish Bull 70(3):715-740

Holeton GF (1972) Gas exchange in fish with and without hemoglobin. Respir Physiol 14(1/2):142-150

Holeton GF (1974) Metabolic cold adaptation of polar fish: fact or artifact? Physiol Zool 47:137-152 
Holeton GF (1980) Oxygen as an environmental factor of fishes. In: Ali MA (ed) Environmental physiology of fishes. Plenum Press, New York, p 7-32

Johnston IA, Battram J (1993) Feeding energetics and metabolism in demersal fish species from Antarctic, temperate and tropical environments. Mar Biol 115:7-14

Johnston IA, Clarke A, Ward P (1991) Temperature and metabolic rate in sedentary fish from the Antarctic, North Sea and Indo-West Pacific Ocean. Mar Biol 109:191-195

Krogh A (1914) The quantitative relation between temperature and standard metabolism in animals. Int Z PhysChem Biol 1:491-508

Macdonald JA, Montgomery JC, Wells RMG (1987) Comparative physiology of Antarctic fishes. Adv Mar Biol 24: 321-388

Munz FW, McFarland WN (1973) The significance of spectral position in the rhodopsins of tropical marine fishes. Vision Res 13:1829-1874

Panten K (1995) Vergleichende Untersuchungen zum Standard- und Aktivitätsstoffwechsel mariner Bodenfische. MSc thesis, University of Hamburg

Saint-Paul U, Hubold G, Ekau W (1988) Acclimation effects on routine oxygen consumption of the Antarctic fish Pogonophryne scotti (Artedidraconidae). Polar Biol 9: 125-128

Smith JLB (1957) The fishes of the family Scorpaenidae in the western Indian Ocean. Ichthyol Bull Rhodes Univ 4:49-88

Smith KL Jr, Brown NO (1983) Oxygen consumption of pelagic juveniles and demersal adults of the deep-sea fish Sebastolobus altivelis, measured at depth. Mar Biol 76: 325-332

Editorial responsibility: Otto Kinne (Editor), Oldendorf/Luhe, Germany
Spoor WA (1946) A quantitative study of the relationship between the activity and oxygen consumption of the goldfish, and its application to the measurement of respiratory metabolism in fishes. Biol Bull 91:312-325

Steffensen JF (1989) Some errors in respirometry of aquatic breathers: how to avoid and correct for them. Fish Physiol Biochem 6(1):49-59

Steffensen JF, Johansen K, Bushnell PG (1984) An automated swimming respirometer. Comp Biochem Physiol 79A: $437-440$

Steffensen JF, Bushnell PG, Schurmann H (1994) Oxygen consumption in four species of teleosts from Greenland: no evidence of metabolic cold adaptation. Polar Biol 14(1): $49-54$

Weiss RF (1970) The solubility of nitrogen, oxygen and argon in water and seawater. Deep-Sea Res 17:721-735

Winberg GG (1956) Rate of metabolism and food requirements of fishes. Beloruss State Univ Minsk, USSR (Fish Res Bd Can Transl Ser 194:1-239, 1960)

Yang TH, Lai NC, Graham JB, Somero GN (1992) Respiratory, blood, and heart enzymatic adaptations of Sebastolobus alascanus (Scorpaenidae; Teleostei) to the oxygen minimum zone: a comparative study. Biol Bull 183:490-499

Zimmermann C (1997) On the ecology of Arctic and Antarctic fish: activity, sensory capabilities and behaviour. Ber Polarforsch 231:1-237 (in German)

Zimmermann C, Hubold G (1998) Respiration and activity of Arctic and Antarctic fish with different modes of life-a multivariate analysis of experimental data. In: di Prisco $G_{\text {, }}$ Pisano E, Clarke A (eds) Fishes of Antarctica. A biological overview. Springer, Milano, p 163-174

Submitted: November 25, 1999; Accepted: January 18, 2001 Proofs received from author(s): August 17, 2001 